\title{
Correspondence
}

\section{Cytomegalovirus Infection Increases the Risk for Inflammatory Bowel Disease}

\section{To the Editor-in-Chief:}

We read with great interest the paper by Onyeagocha et $\mathrm{al}^{1}$ that describes their studies on the relationship between cytomegalovirus (CMV) and inflammatory bowel disease (IBD). In recent years, there has been a lot of attention on the role of CMV infection in patients with IBD. However, most studies focus on the role of CMV as an exacerbating factor in an already inflamed colon. The precise role of CMV infection in the clinical course of IBD as well as its therapeutic consequences remains to be elucidated.

In their elegant study, Onyeagocha et al focused on the role of CMV infection as a trigger for the development of IBD in susceptible hosts and as a cofactor to other known triggers of IBD. The authors showed in an animal study that previous CMV infection increases the susceptibility to developing acute colitis after exposure to dextran sulfate sodium. They also showed that this increased risk is not due to infection of the intestine by the virus itself. Indeed, the observed increase in intestinal permeability associated with CMV infection could be the responsible mechanism.

The role of CMV infection as a trigger for the development of IBD has been the subject of previous human studies as well. In 2006, we studied the role of CMV infection after liver transplantation as well as its effect on inflammatory bowel disease., ${ }^{2,3}$ In patients with known $\mathrm{IBD}$ or at a high risk for IBD, CMV infection after transplantation was a strong and independent predictor for the development of both recurrent and de novo IBD. Interestingly, our studies also showed that this effect was not associated with actual CMV colitis. This is in line with the findings of Onyeagocha et al, and we agree with the authors that intestinal permeability could be the precipitating mechanism. In solid organ transplant recipients,
CMV infection is known to increase gut permeability. ${ }^{4}$ Other potential mechanisms include increased expression of vascular cell adhesion molecule-1, up-regulation of major histocompatibility complex 1 , or increased interleukin-6 production. ${ }^{2}$

We feel that the findings of Onyeagocha et al add to our previous clinical findings and that the precise mechanisms through which CMV infection increases the risk for IBD are a very interesting subject for further studies.

Robert C. Verdonk Elizabeth B. Haagsma Jan H. Kleibeuker Gerard Dijkstra

University Medical Centre Groningen Groningen, The Netherlands

Debra L. Sudan

Duke University Medical Center

Durham, North Carolina

\section{References}

1. Onyeagocha C, Hossain MS, Kumar A, Jones RM, Roback J, Gewirtz AT: Latent cytomegalovirus infection exacerbates experimental colitis. Am J Pathol 2009, 175:2034-2042

2. Verdonk RC, Haagsma EB, Van Den Berg AP, Karrenbeld A, Slooff MJ, Kleibeuker JH, Dijkstra G: Inflammatory bowel disease after liver transplantation: a role for cytomegalovirus infection. Scand J Gastroenterol 2006, 41:205-211

3. Verdonk RC, Dijkstra G, Haagsma EB, Shostrom VK, Van den Berg AP Kleibeuker JH, Langnas AN, Sudan DL: Inflammatory bowel disease after liver transplantation: risk factors for recurrence and de novo disease. Am J Transpl 2006, 6:1422-1429

4. de Maar EF, Kleibeuker JH, Boersma-van Ek W, The TH, van Son WJ: Increased intestinal permeability during cytomegalovirus infection in renal transplant recipients. Transplant Int 1996, 9:576-580 